\title{
Evaluation of Bronchoscopic Lung Insufflation in the Management of Patients with Lung Collapse
}

\author{
ABBAS S. EL-MARAGHY, M.D.; AHMED A. ABU NAGLAH, M.D.; MOUSTAFA A. ZEDAN, M.D. and \\ SAMEH U. NOUR, M.Sc.
}

The Department of Chest Diseases, Faculty of Medicine, Al-Azhar University, Cairo, Egypt

\begin{abstract}
Background: Pulmonary atelectasis is one of the most commonly encountered abnormalities in chest radiographs. Flexible Bronchoscopy (FB) has been of great help in the management of many pulmonary conditions. Bronchoscopic insufflation of atelectatic portions of the lung can be safe and effective in treating acute lung collapse which is refractory to conventional therapy.
\end{abstract}

Aim of Study: To evaluate the safety and effectiveness of bronchoscopic lung insufflation in the management of Egyptian patients with lung collapse.

Subjects and Methods: An experimental cross-sectional study was carried out on 40 patients admitted in Al-Hussein and Sayed Galal Al-Azhar University Hospitals in the period from March 2016 to March 2018. Patients with acute partial or complete lung collapse that failed to re-expand with conventional methods (physiotherapy or lung recruitment manoeuvers) or those with rapidly aggravated collapse were included. The patients, after failed conventional methods, were categorized into two groups: Group 1: Included thirtysix patients managed by bronchoscopic toilet and suction only. (Thirty patients with success bronchoscopic suction and six patients whom collapse failed to expand with bronchoscopic suction). Group 2: Include ten patients managed by bronchoscopic insufflation technique either immediately in cases of rapidly aggravated collapse (four patients) or after failed initial bronchoscopic toilet and suction (six patients).

Results: Thoracic and upper abdominal operations caused significant numbers of postoperative lung collapse with lower lobes mostly affected. The mean value of $\mathrm{PaO}_{2}$ was significantly improved after the bronchoscopic insufflation procedure ( $74.3 \pm 10.4$ vs. $60.9 \pm 9.7 \mathrm{mmHg}, p<0.001)$. The success rate of bronchoscopic insufflation was $80 \%$ in the first 24 hours with no significant procedure-related complications. Recurrence of collapse within 2 weeks follow-up was noted in preexisting pulmonary disease, but was significant in smokers $(p=0.022)$. Late intervention after 72 hours was associated with failed lung expansion.

Correspondence to: Dr. Sameh U. Nour, The Department of Chest Diseases, Faculty of Medicine, Al-Azhar University, Cairo, Egypt
Conclusion: Bronchoscopic insufflation was highly successful in treating lung collapse and improving lung oxygenation without significant complications.

Key Words: Lung collapse - Bronchoscopic insufflation.

\section{Introduction}

LUNG collapse or atelectasis is loss of volume of a lung, lobe, or segment mainly due to obstruction of a major bronchus by tumor, foreign body, or bronchial plug [1]. Management of lung collapse depends firstly on non-pharmacologic therapies for improving cough and clearance of secretions from the airways [2]. Alveolar recruitment manoeuvres aimed at opening unstable airless alveoli thus increasing end-expiratory lung volume and improving gas exchange [3]. Bronchoscopic insufflation of atelectatic portions of the lung has been also described. It can be safe and effective in treating acute lung collapse which is refractory to conventional therapy [4]. The idea of insufflation is based conceptually on the idea that while mucus plugs may lead to atelectasis, their removal may not be sufficient to correct the defect. The addition of high pressures may overcome the high critical opening pressure and reduced lung compliance of the atelectatic lung [5].

\section{Subjects and Methods}

Design and setting: An experimental crosssectional study was carried out on 40 Egyptian patients (16 females and 24 males) admitted in AlHussein and Sayed Galal Al-Azhar University Hospitals in the period from March 2016 to March 2018. Patients with acute lung collapse that failed to re-expand with conventional methods (chest physiotherapy or lung recruitment manoeuvers) were included. 
All studied cases were subjected to: Full history taking, clinical examination, chest X-ray before and after the procedure, thoracic ultrasound, arterial blood gas analysis, C.T. chest, and a trial to treat the collapse by non-invasive techniques. If these measures failed to fully or partially re-expand the collapsed area, fiberoptic bronchoscopic suction was done and if failed, fiberoptic bronchoscopic lung insufflation was done. Insufflation was also immediately considered in rapidly aggravated collapse. The patient was monitored during the procedure and followed-up 2 weeks after the procedure. The patients, after failed conventional methods, were categorized into two groups: Group 1: Included thirty-six patients managed by bronchoscopic toilet and suction only. (Thirty patients with success bronchoscopic suction and six patients whom collapse failed to expand with bronchoscopic suction). Group 2: Include ten patients managed by bronchoscopic insufflation technique either immediately in cases of rapidly aggravated collapse (four patients) or after failed initial bronchoscopic toilet and suction (six patients).

Exclusion criteria include: (1) Patients with obstructive lung collapse due to endobronchial obstruction by foreign body or tissue occluding the airway. (2) Patients with lung collapse due to extra-bronchial compression by tumor, lymph node, or pleural problems (e.g. effusion or pneumothorax). (3) Patients with reduced lung compliance who might not tolerate pressurized insufflation technique (like ARDS). (4) Patients with longstanding collapse.

The device: Rubber three-way connections; one way connected to pressure manometer, 2 nd way was connected to inflation bulb of a sphygmomanometer, while the ${ }^{3 r d}$ way was connected to the working channel of the bronchoscope and the components were tightly sealed to avoid air leaks. Fig. (1).

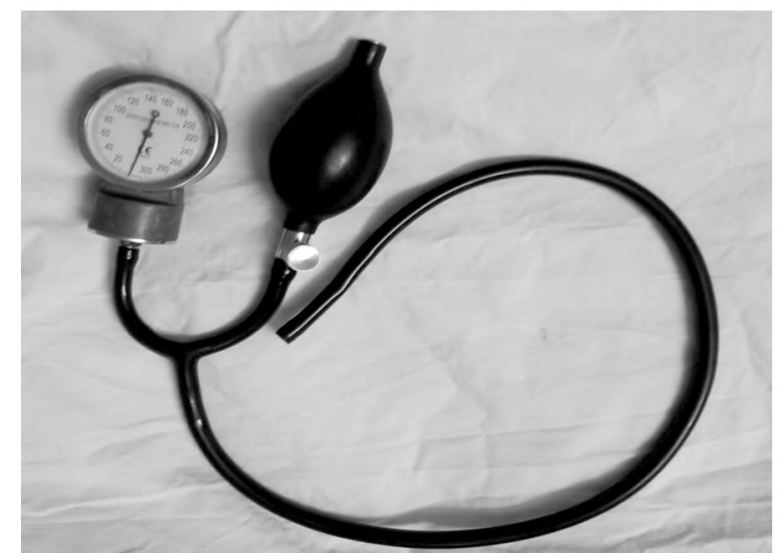

Fig. (1): Insufflation device with three way rubber connections.

\section{Procedure:}

The monitored patient was laying supine after I.V. access was obtained. Topical analgesic was applied to the nose and pharynx with or without conscious sedation according to the patient status. Bronchoscope was advanced through the patient airways toward the collapsed area, and then was wedged into the collapsed segment or all the segments of the collapsed lobe and insufflation was done 5-10 times at regular intervals under pressure not exceeding $20 \mathrm{mmHg}$ to avoid barotrauma and the patient hemodynamics were monitored. An inflation bulb with attached manometer was used and a maximum of five insufflations in two minutes were done to relieve most collapses.

\section{Ethical consideration:}

Ethical clearance was obtained from the Research Ethical Committee at Al-Hussein University Hospital. Procedures were performed after obtaining a signed written informed consent from patients or their relatives. Privacy and confidentiality were maintained throughout the study process. Subjects or their relatives received written notification of the intervention results.

\section{Statistical analysis:}

Data were analyzed using the SPSS computer package Version 21.0 (SPSS Inc., Chicago, IL, USA). For descriptive statistics; the mean \pm SD was used for quantitative variables while the number and percentage were ${ }_{2}$ used for qualitative variables. Chi-square test $\left(\chi^{2}\right)$ was used to assess the differences in frequency of qualitative variables while Fisher's Exact Test (FET) was applied if any expected cell values in a 2 X 2 table was $<5$. Paired samples $t$-test was applied in order to assess the differences in means of quantitative variables. The statistical methods were verified, assuming a significant level of $p<0.05$.

\section{Results}

The study included 40 patients (24 males and 16 females) with mean age $58.2 \pm 6.7$ years and $52.5 \%$ of them were smokers. About $35 \%$ of patients were having pre-existing pulmonary disease and $65 \%$ presented mainly by acute dyspnea (with or without hypoxemia) while $35 \%$ were presented mainly by acute chest pain. In $55 \%$ of patients, the cause of collapse was post-operative (mainly cardio-thoracic, 8 out of 22 patients) and $30 \%$ due to neurological disorders while the remaining collaps- 
es were due to respiratory causes. About $67.5 \%$ had lobar collapse and $32.5 \%$ with total lung collapse. Lower lobes were the site of collapse among nearly $42.5 \%$ of patients while middle lobe/lingula contributed to nearly $22.5 \%$. Table (1).

Table (1): Different characteristics of collapse among the studied sample.

\begin{tabular}{|c|c|c|}
\hline & $\begin{array}{l}\text { Frequency } \\
\quad(\mathrm{n}=40)\end{array}$ & $\begin{array}{l}\text { Percent } \\
(\%)\end{array}$ \\
\hline \multicolumn{3}{|l|}{ Pre-existing pulmonary disease: } \\
\hline Yes & 14 & 35 \\
\hline No & 26 & 65 \\
\hline \multicolumn{3}{|l|}{ Main presentation: } \\
\hline Acute dyspnea without hypoxemia & 16 & 40 \\
\hline Acute dyspnea with acute hypoxemia & 10 & 25 \\
\hline Acute chest pain & 14 & 35 \\
\hline \multicolumn{3}{|l|}{ Causes of collapse: } \\
\hline Respiratory disorder & 6 & 15 \\
\hline Neurological disorder & 12 & 30 \\
\hline Post-operative* & 22 & 55 \\
\hline \multicolumn{3}{|l|}{ Type of collapse: } \\
\hline Lobar collapse & 27 & 67.5 \\
\hline Total lung collapse & 13 & 32.5 \\
\hline \multicolumn{3}{|l|}{ Site of collapse: } \\
\hline Lower lobes & 17 & 42.5 \\
\hline Upper lobes & 1 & 2.5 \\
\hline Middle lobe/lingula & 9 & 22.5 \\
\hline Total lung collapse & 13 & 32.5 \\
\hline
\end{tabular}

In majority of patients $(60 \%)$, failed conventional methods were the indication of bronchoscopic insufflation and $40 \%$ due to rapidly aggravated collapse. The both bronchoscopic procedures were complicated by more oxygen desaturation in $25 \%$ while $75 \%$ showed no complications and the insufflation succeeded to treat collapse and no recurrence occurred in $80 \%$ of patients within 2 weeks followup after complete lung inflation on discharge while $20 \%$ showed recurrence. $\mathrm{PaO}_{2}$ on room air was significantly improved after insufflation $(74.3 \pm 10.4$ vs. $60.9 \pm 9.7 \mathrm{mmHg}, p<0.001)$. Failure of reexpansion within 24 hours noticed in $20 \%$, while $80 \%$ showed successful re-expansion and intervention within the first 72 hours occurred in $90 \%$ compared to $10 \%$ after 72 hours (Table 2).
Table (2): Bronchoscopic procedures among the studied sample.

\begin{tabular}{|c|c|c|}
\hline & $\begin{array}{l}\text { Frequency } \\
\quad(\mathrm{n}=40)\end{array}$ & $\begin{array}{l}\text { Percent } \\
(\%)\end{array}$ \\
\hline \multicolumn{3}{|l|}{ Indication of bronchoscopic insufflation: } \\
\hline Failed conventional methods & 6 & 60 \\
\hline Rapidly aggravated collapse & 4 & 40 \\
\hline \multicolumn{3}{|l|}{ Complication of bronchoscopic procedures: } \\
\hline More desaturation during the procedure & 10 & 25 \\
\hline No & 30 & 75 \\
\hline \multicolumn{3}{|l|}{$\begin{array}{l}\text { Recurrent collapse within } 2 \text { weeks follow- } \\
\text { up among bronchoscopic insufflation group: }\end{array}$} \\
\hline Yes & 2 & 20 \\
\hline No & 8 & 80 \\
\hline \multicolumn{3}{|l|}{$\mathrm{PaO} 2$ on room air $(\mathrm{mmHg})$ among } \\
\hline insufflation group : & \multicolumn{2}{|l|}{$60.9 \pm 9.7$} \\
\hline Before procedure & \multicolumn{2}{|l|}{$74.3 \pm 10.4$} \\
\hline After procedure & \multicolumn{2}{|l|}{$(p<0.001 *)$} \\
\hline \multicolumn{3}{|l|}{$\begin{array}{l}\text { Failure of re-expansion within } 24 \text { hours } \\
\text { among insufflation group: }\end{array}$} \\
\hline Yes & 2 & 20.0 \\
\hline No & 8 & 80.0 \\
\hline \multicolumn{3}{|l|}{ Time of intervention among both groups: } \\
\hline Within 72 hours & 36 & 90 \\
\hline After 72 hours & 4 & 10 \\
\hline
\end{tabular}

In all our patients, re-expansion of collapse within $24 \mathrm{hs}$ was significantly successful with bronchoscopic insufflation when the time of intervention was in the 1 st 72 hours, compared to failure of re-expansion in all patients when intervention was delayed after 72 hours. Fig. (2).

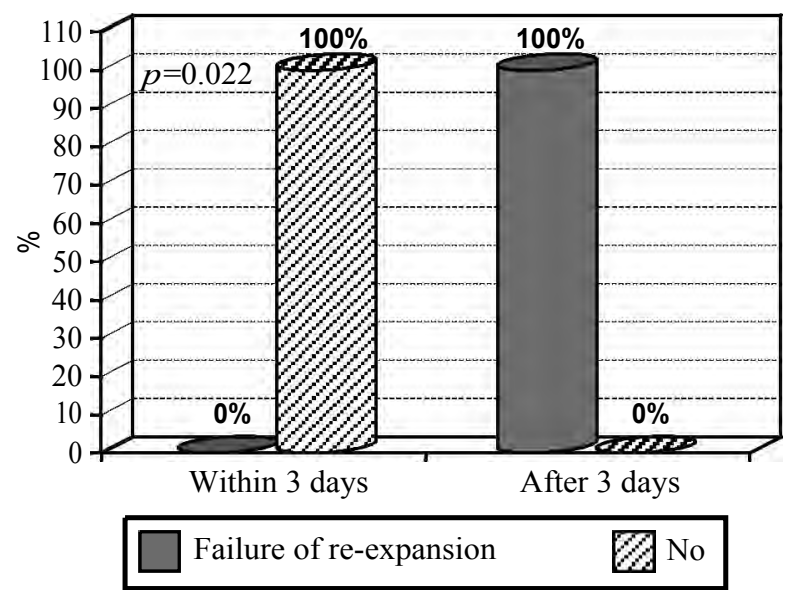

Fig. (2): Relation between failure of re-expansion within 24 hours and time of intervention.

When exploring complications of the procedures, more desaturation was significantly noticed in patients with pre-existing pulmonary diseases, while it showed no statistical difference according to the type of procedure or smoking habit. Table (3). 
Table (3): Risk factors for recurrent collapse within 2 weeks follow-up among the studied sample.

\begin{tabular}{|c|c|c|c|c|}
\hline & \multicolumn{2}{|c|}{$\begin{array}{l}\text { More desaturation } \\
\text { during the procedure }\end{array}$} & \multirow{2}{*}{$\begin{array}{l}\chi^{2} / \\
\text { FET }\end{array}$} & \multirow{2}{*}{$\begin{array}{c}p- \\
\text { value }\end{array}$} \\
\hline & Yes & No & & \\
\hline \multicolumn{5}{|l|}{ Smoking habit: } \\
\hline Smoker & $5(23.8)$ & $16(76.2)$ & 0.03 & 1.000 \\
\hline Non smokers & $5(26.3)$ & $14(73.7)$ & & \\
\hline \multicolumn{5}{|l|}{ Type of procedure: } \\
\hline Bronchoscopic insufflation & $4(40.0)$ & $6 \quad(60.0)$ & 0.9 & 0.435 \\
\hline Bronchoscopic suction & $9(25.0)$ & $27(75.0)$ & & \\
\hline \multicolumn{5}{|l|}{ Pre-existing pulmonary disease: } \\
\hline Yes & $8(80.0)$ & $6 \quad(20.0)$ & 14.3 & $<0.003^{*}$ \\
\hline No & $2(20.0)$ & $24(80.0)$ & & \\
\hline
\end{tabular}

Our results showed that among 8 patients who developed recurrent collapse within 2 weeks followup ( 2 among insufflation group and 6 among bronchoscopic suction group), $75 \%$ were smokers with statistical significance. Fig. (3).

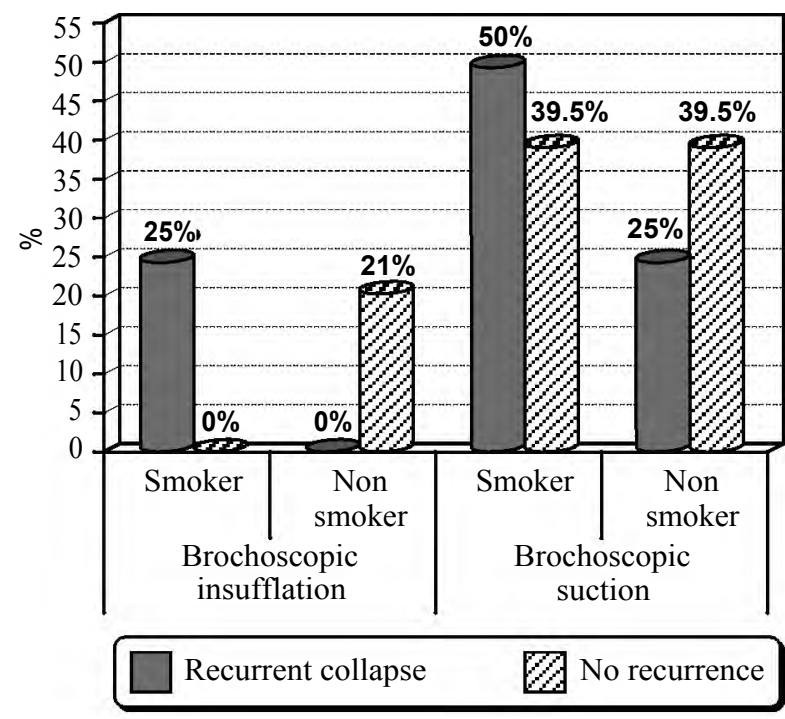

Fig. (3):

\section{Discussion}

Lung collapse (atelectasis) is one of the most commonly encountered abnormalities in chest radiographs [6]. Bronchoscopy has been identified as an important and safe tool to treat lung collapse in case of a lack of response to physical therapy or worsening atelectasis. However, the atelectatic segments may not expand, so the use of air insufflation in addition to standard bronchoscopy for the treatment of atelectasis was devised to overcome this problem [7].

Our results showed that more than half $(55 \%)$ of our patients developed postoperative lung col- lapse and $35 \%$ of them were having pre-existing pulmonary disease. This was similar to the literature and other studies $[\mathbf{8 , 9}]$. Similarly, Niyayeh-Saffari et al. found that $32.8 \%$ of Iranian patients had at least one type of atelectasis within the first three days after the surgery and that pre-operative pulmonary diseases like asthma, bronchitis, etc increase the risk of postoperative atelectasis [10]

Post-operative atelectasis develops due to decreased compliance of lung tissue, impaired regional ventilation, retained airway secretions and postoperative pain that interferes with spontaneous deep breathing and coughing [11]

Cardiothoracic and upper abdominal surgeries caused atelectasis in $36.4 \%$ and $31.8 \%$ of all our post-operative atelectasis. Serejo et al., prospectively studied the risk factors for pulmonary complications after emergency abdominal surgery and found that 75 out of $266(28.2 \%)$ of patients developed post-operative pulmonary complications from which 16 patients $(21.3 \%)$ developed lung atelectasis [12]. Some other studies found that the incidence of post-operative atelectasis was higher after thoracic surgery than that after abdominal or peripheral surgery $[11,13]$. The percentage was shooting as high as $90 \%$ in cardiac surgical patients [14]

Thirty percent of patients developed atelectasis as a result of neurological disorders. This finding coincides with Karanjia et al., who studied the clinical description of extubation failure in patients with primary brain injury and found that lung atelectasis was observed in $39 \%$ of their patients [15] .

Lobar collapse was the most frequent type among our patients $(67.5 \%)$ and lower lung zones were much affected by atelectasis $(42.5 \%)$. Lung bases and posterior segments are vulnerable to dependent atelectasis [9]. Similar results were reported by Verheij et al., [16] in their review of pulmonary abnormalities after cardiac surgery with $46 \%$ of their patients showed left lower lobe collapse and by Pulletz et al., [17] who found that most areas of atelectasis were more noticed in the dependent lung zones specially the lower lobes.

Most of our patients (60\%) were subjected to bronchoscopic insufflation due to failed conventional methods (chest physiotherapy and lung recruitment manoeuvers). Respiratory physiotherapy in hospitalized patients including postural drainage, chest wall percussion and vibration, and a forced expiration technique has been largely ignored leading to increased respiratory complications and the abuse of invasive treatment proce- 
dures, such as bronchoscopy. On the other hand, selective recruitment of collapse utilizing bronchoscopic insufflation improves "targeted" lung volume and oxygenation with fewer hemodynamic effects. Additionally, bronchoscopic insufflation is useful in non-intubated patients who are unable to participate in chest physiotherapy due to altered mental status, chest wall pain and the morbidly obese [2]

The mean $\mathrm{PaO} 2$ on room air has significantly improved $(74.3 \pm 10.4$ vs. $60.9 \pm 9.7 \mathrm{mmHg}, p<0.001)$ after the insufflation procedure among our patients. Similar significant improvement was reported by Wohlauer et al., with mean $\mathrm{PaO}_{2}: \mathrm{FiO}_{2}$ increased from 135 to 206 [18]

In about $80 \%$ of our patients subjected to insufflation, the procedure succeeded to treat collapse and no recurrence occurred within 2 weeks followup. While bronchoscopic suction was successful with no recurrence in the same period in $86 \%$ of patients subjected to bronchoscopic suction. Jelic et al., reported that atelectasis recurs frequently after bronchoscopy because the cause of compromised airway hygiene continues. Thus, failure to resolve the primary problem should not be an indication for repeated invasive intervention in the airways [19].

Our result showed that success rate of bronchoscopic insufflation was $80 \%$ in the first 24 hours. When using wedged flexible bronchoscopic insufflation technique, Wohlauer et al., showed $100 \%$ success rate on his work on 16 patients [18]. In another successful report of selective intrabronchial air insufflation, Abtahi et al., used recruitment bronchoscopy by trans-glottic approach to successfully treat lung collapse in an intubated mechanically ventilated patient [7]. Also, Abu-Hasan et al., reported successful use of bronchoscopic lung insufflation to treat left lung atelectasis by injecting $200 \mathrm{ml}$ room air followed by $200 \mathrm{ml}$ surfactant into the collapsed area through the wedged bronchoscope [4]

Apart from transient tachycardia and hypotension in some cases, most of the above researchers found that bronchoscopic insufflation technique is safe with no significant complications found like pneumothorax, alveolar hemorrhage or air dissected into vessels except some deaths related to the original insult and was not due to the procedure itself. However, we reported more oxygen desaturation during procedures in $25 \%$ of cases. This may be attributed to the sedation injected and/or underlying lung disease, as $80 \%$ of the insufflated group and $20 \%$ of the suction group were having pre-existing chronic pulmonary diseases and all of them were already hypoxemic.

Our results showed that smokers were subjected more to failure of re-expansion within 24 hours after the procedure and procedure complication than non-smokers but without significant difference between them. This finding was similar to that concluded by Graybill et al., in their review about the impact of smoking on perioperative pulmonary and upper respiratory complications after laparoscopic gynecologic surgery [20]. They owed the results to that laporoscopic surgery is simpler than open surgery with overall fewer complications and less anesthetic time. However, Hoshikawa and Tochii on their study on postoperative atelectasis and pneumonia after general thoracic surgery considered smoking cessation, in addition to other measures, are among strategies to reduce the risk of postoperative pulmonary complications including these two disorders [21]. The difference between our study and this study may be attributed to small sample size and many females in our study with the fact of many being non-smokers.

Our results considered smoking as a significant risk factor for recurrence of atelectasis after the two procedures. Many studies discussed the mechanism of smoking in atelectasis. Smoking affects the lung at various loci including the bronchi, bronchioles and the lung parenchyma. It alters both the structure and function of the bronchial mucus glands. Exposure to smoke increases both the number and size of these mucus-secreting glands, resulting in the production and deposition of excess mucus within the lumen of the airway. In response to enlarged, hyperactive mucus glands, as well as to the influx of inflammatory cells, the airway walls become thickened. Correspondingly, the diameter of the airway lumen is reduced and may more easily become congested or plugged with mucus and accordingly atelectasis ensues [22,23]

This study was subjected to some limitations; as a cross-sectional study it does not determine the cause-effect relationship, the small sample size, Also, as comparing bronchoscopic suction and insufflation groups, some patients were different according to age, sex, atelectasis site and extent, and underlying pulmonary disease which may give rise to data bias. Moreover, some patients had multiple organ dysfunctions that might affect the respiratory function and the outcome of the procedure that might affect the generalization of our results. 


\section{Conclusion:}

The study tried to give insight into the safe usage of flexible fiberoptic bronchoscopic insufflation whenever indicated and the occurrence of complications were minor and self-limiting. Appropriate preparation, close supervision and adherence to the guidelines were essential for a successful and safe procedure.

\section{References}

1- KAMINSKY D.: Diseases and Pathology Congenital Lung Disease. In: Netter Collection of Medical Illustrations: Respiratory System. Kaminsky D., O'grady E., Thiel M. (eds.), 2nd edition, Volume 3, Section 4, Pp: 176-82. Elsevier, Saunders, 2011.

2- McCOOL F. and ROSEN M.: Nonpharmacologic airway clearance therapies: ACCP evidence-based clinical practice guidelines. Chest, 129 (1): 250-9, 2006.

3- PELOSI P., GAMA De ABREU M. and ROCCO P.: New and conventional strategies for lung recruitment in acute respiratory distress syndrome. Crit. Care, 14 (2): 210, 2010.

4- ABU-HASAN M., CHESROWN S. and JANTZ M.: Successful Use of Bronchoscopic Lung Insufflation to Treat Left Lung Atelectasis. Pediatr. Pulmonol., 48 (3): 306-9, 2013.

5- KREIDER M. and LIPSON D.: Bronchoscopy for atelectasis in the ICU: A case report and review of the literature. Chest, 124 (1): 344-50, 2003.

6- RESTREPO R. and BRAVERMAN J.: Current challenges in the recognition, prevention and treatment of perioperative pulmonary atelectasis. Expert. Rev. Respir. Med., 9 (1): 97-107, 2015.

7- ABTAHI H., GHARABAGHI M. and AZIMI M.: Recruitment bronchoscopy by trans-glottic approach successfully treated lung collapse in an intubated mechanically ventilated patient. B.M.J. Case Rep., doi: 10.1136/bcr-2013200177, 2013.

8- CANET J. and MAZO V.: Post-operative pulmonary complications. Minerva Anestesiol., 76 (2): 138-43, 2010.

9- O'DONNELL A.: Bronchiectasis, atelectasis, cysts, and localized lung disorders. In: Cecil Medicine. Goldman L, Schafer AI, (Eds), 24th edition, Philadelphia, Pa: Saunders Elsevier, chapter 90, pp: 548-51, 2011.

10-NIYAYEH-SAFFARI N., NASIRI E., MOUSAVINASAB S., et al.: Frequency Rate of Atelectasis in Patients Fol- lowing Coronary Artery Bypass Graft and Its Associated Factors at Mazandaran Heart Center in 2013-2014. Glob. J. Health Sci., 7 (7): 97-105, 2015.

11- SENGUPTA S.: Post-operative pulmonary complications after thoracotomy. Indian J. Anaesth., 59 (9): 618-26, 2015.

12- SEREJO L., Da SILVA-JÚNIOR F., BASTOS J., et al. Risk factors for pulmonary complications after emergency abdominal surgery. Respir. Med., 101 (4): 808-13, 2007.

13- BRANSON R.: The scientific basis for post-operative respiratory care. Respir. Care, 58 (11): 1974-84, 2013.

14- JOSHI P., FRASER J. and MULLANY D.: The high risk cardiac surgical patient. Curr. Anaesth. Crit. Care, 16 (6): 369-83, 2005

15- KARANJIA N., NORDQUIST D., STEVENS R., et al.: A Clinical Description of Extubation Failure in Patients with Primary Brain Injury. Neurocrit Care, 15 (1): 4-12, 2011.

16- VERHEIJ J., VAN LINGEN A., RAIJMAKERS P., et al.: Pulmonary abnormalities after cardiac surgery are better explained by atelectasis than by increased permeability oedema. Acta Anaesthesiol. Scand., 49 (9): 1302-10, 2005.

17- PULLETZ S., ADLER A., KOTT M., et al.: Regional lung opening and closing pressures in patients with acute lung injury. J. Crit. Care, 27 (3): 323.e11-8, 2012.

18- WOHLAUER M., MOORE E., HAENEL J., et al.: Selective intrabronchial air insufflation for acute lobar collapse in the Surgical Intensive Care Unit. J. Surg. Radiol., 2 (2): 178-80, 2011.

19- JELIC S., CUNNINGHAM J. and FACTOR P.: Clinical review: Airway hygiene in the Intensive Care Unit. Crit. Care, 12 (2): 209, 2008.

20- GRAYBILL W., FRUMOVITZ M., NICK A., et al.: Impact of smoking on perioperative pulmonary and upper respiratory complications after laparoscopic gynecologic surgery. Gynecol. Oncol., 125 (3): 556-60, 2012.

21- HOSHIKAWA Y. and TOCHII D.: Post-operative Atelectasis and Pneumonia after General Thoracic Surgery. Kyobu Geka., 70 (8): 649-55, 2017.

22- DEMLING R.: Smoke Inhalation Lung Injury: An Update. Eplasty; 8: e27, 2008.

23- CANET J., GALLART L., GOMAR C., et al.: Prediction of post-operative pulmonary complications in a populationbased surgical cohort. Anesthesiology, 113 (6): 1338-50, 2010. 


\section{تقيييم دفع الهواء بالمنظار الشعبى

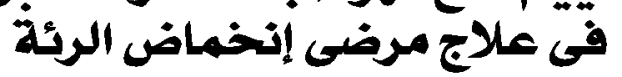

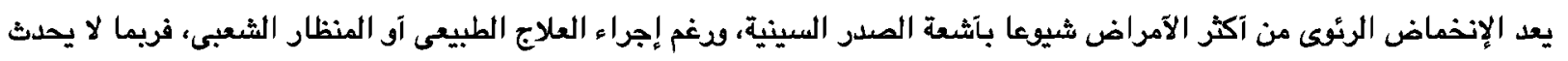

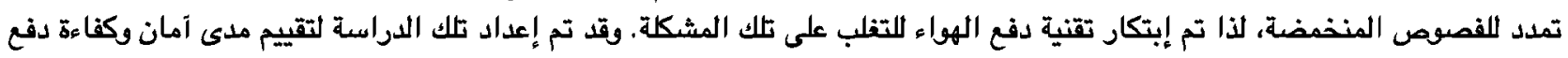

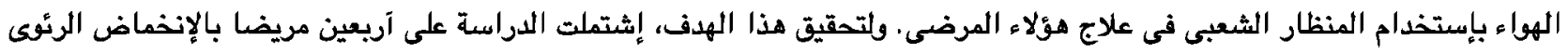

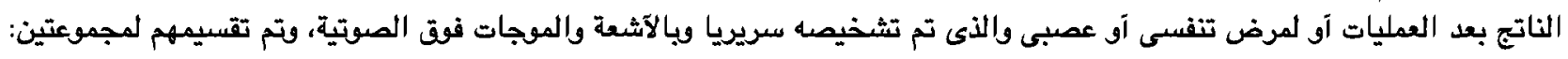

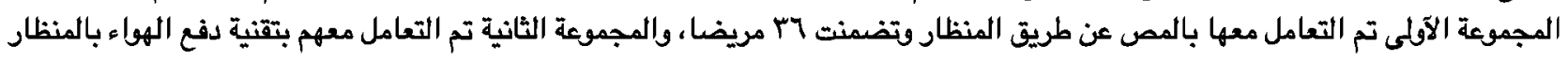

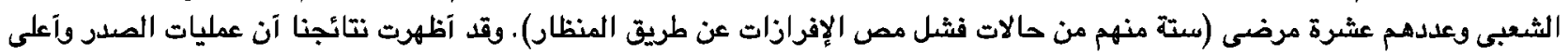

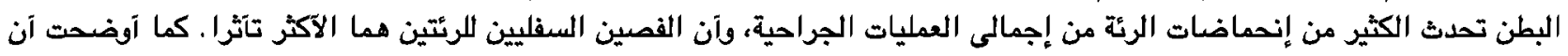

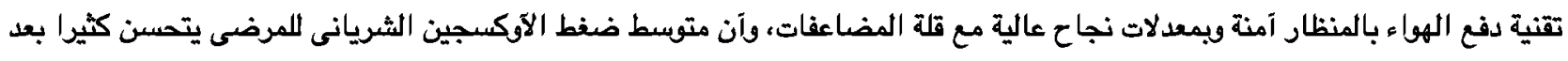

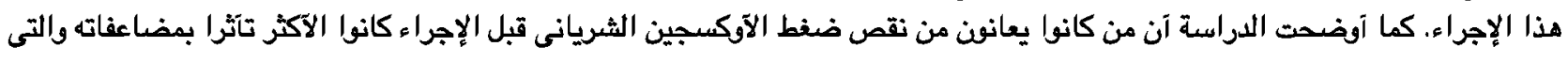

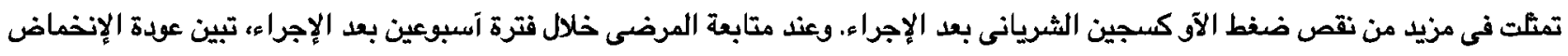

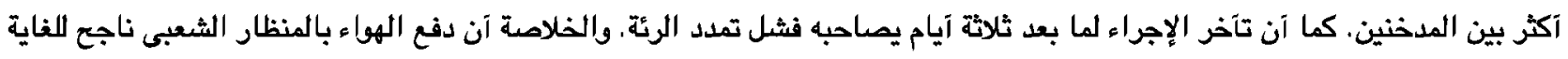

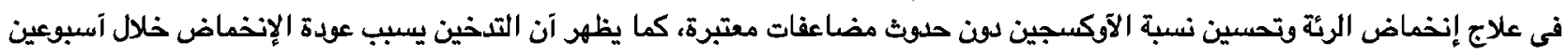

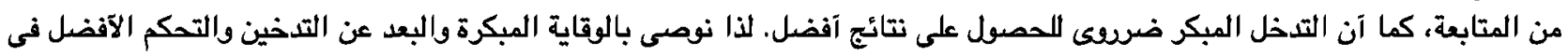

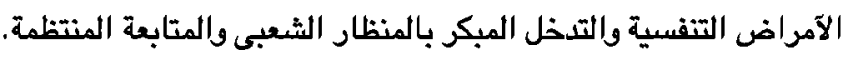

